\title{
A Review on Covid-19, Symptoms, Epidemiology, Pathogenesis and future Challenges
}

Fouzia Parveen ${ }^{1}$, Musawir Hussain ${ }^{7 *}$, Nelofar Ansari ${ }^{6}$, Zainab Arshad ${ }^{3}$, Muhammmad Haroon ${ }^{5}$, Muhammmad Ammar ${ }^{4}$, Shahid Ali Chand ${ }^{4}$, Hira Ghaffar ${ }^{2}$

${ }^{1}$ Department of Intensive Care Unit (Staff Nurse), Faisalabad Institute of Cardiology, Faisalabad

${ }^{2}$ Department of Applied Psychology, University of Sahiwal, Sahiwal

${ }^{3}$ Department of Zoology, Wildlife and Fisheries, University of Agriculture, Faisalabad

${ }^{4}$ Department of Plant Pathology, University of Agriculture, Faisalabad

${ }^{5}$ Health Department, Punjab Medical Faculty, Lahore

${ }^{6}$ Department of Botany, University of Balochistan, Pakistan

${ }^{7}$ Department of Botany, University of Agriculture, Faisalabad

DOI: 1 10.36348/sijb.2020.v03i05.002 $\quad$ | Received: 01.05.2020 | Accepted: 09.05.2020 | Published: 14.05 .2020

*Corresponding author: Fouzia Parveen

\section{Abstract}

Mainly, SARS-CoV is transmitted through inhalation of respiratory droplets and direct or indirect contact. The Covid-19 has become the biggest pathogens of emerging respiratory disease outburst. These pathogens are a large family of RNA viruses that is single stranded that can be isolated in a lot of different animal species. The complete information about epidemiology, pathogenesis of Covid-19 remains unclear. There is need to study clear diagnosis and pathogenesis of this virus. The symptoms of COVID-19 infection started to appear after an incubation period of almost 5.2 days. The period from the attack of COVID-19 symptoms to death are ranged from 6 to 41 days with an average of 14 days. The patients $>70$-years old had shorter incubation period compared with those who are the under the age of 70 . The most common symptoms at attack of COVID-19 dry cough, illness are fever, and fatigue, while other symptoms include sputum production in lungs, diarrhea, headache, hemoptysis, lymphopenia and dyspnea. The patients infected with COVID-19 showed high number of leukocytes, abnormal respiratory findings and with pro-inflammatory cytokines. Rapid reconstruction of SARS-CoV-2, and technical advancement is very helpful for development of vaccine. Rhesus monkey human ACE2 transgenic mouse for development of vaccine, and some SARS-CoV-2 vaccines are already under experimental clinical trial. Probably, the mechanism of vaccination offers the best option to control COVID-19.

Keywords: COVID-19, Epidemiology, SARS-CoV, transmission, vaccine development.

Copyright @ 2020: This is an open-access article distributed under the terms of the Creative Commons Attribution license which permits unrestricted use, distribution, and reproduction in any medium for non-commercial use (NonCommercial, or CC-BY-NC) provided the original author and source are credited.

\section{INTRODUCTION}

The recent flutter of the novel coronavirus SARSCoV-2 (coronavirus disease 2019; previously 2019- nCoV), Centre in Hubei Province of the People's Republic of China, has spread out to many of the neighboring and even non neighboring other countries. Johns Hopkins University and other forums have provided the cases detection rate that are changing daily[1].

The CoVs have become the biggest pathogens of emerging respiratory disease outburst[2]. These pathogens are a large family of RNA viruses that is single stranded that can be isolated in a lot of different animal species. For reasons which to be explained, these viruses can cross all species barriers and can cause disease in humans, illness pasturing from the common cold to most severe diseases such as SARS and MERS[3]. Attractively, these dangerous viruses have cmae from sources by animals such as bats and then moving into other different mammalian hosts like the Himalayan palm civet for SARS-CoV, and the dromedary camel for MERS-CoV- before moving to humans[4]. The energetics of SARS-Cov-2 are currently unknown, but there is adventure that it also has an animal origin[5]. 


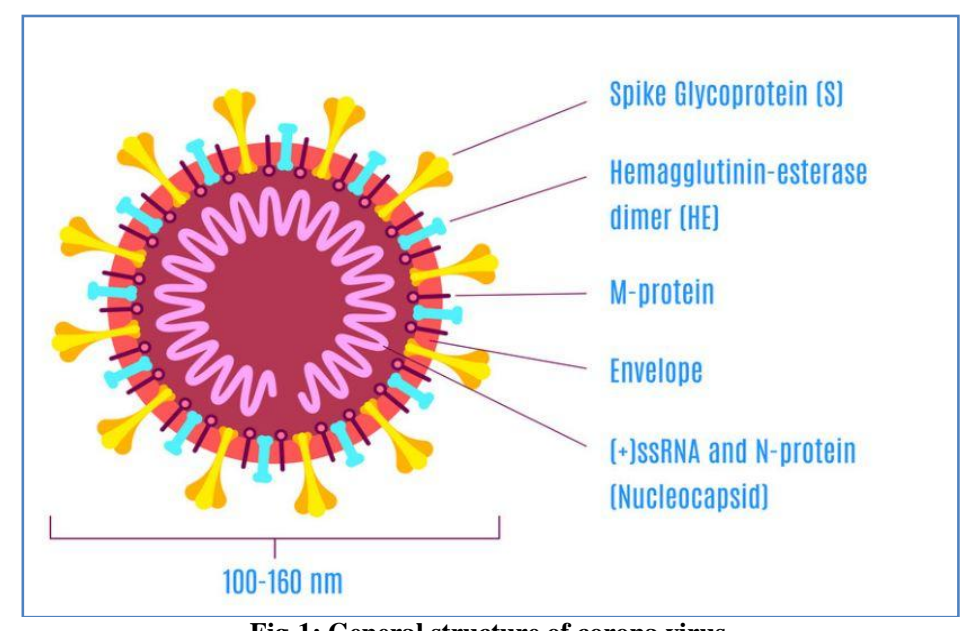

Fig-1: General structure of corona virus

There are many reports about the emergence of COVID-19 that have started to answer many clinical questions, including outcomes and evolution as well as potential hazard factors, and laboratory, clinical and image findings. Although many of the different reviews usually including randomized clinical trials (RCTs) and aim to provide a more accurate estimate of the impact of a treatment or hazard factor for diseases, also have been wide-ranging used to create the observational studies[6]. In many conditions, RCTs are not available or feasible, and the only data taken from observational studies are considered accessible. This is the case for the laboratory, clinical and image features of COVID19. The complete information about epidemiology, pathogenesis of Covid-19 remains unclear. There is need to study clear diagnosis and pathogenesis of this virus.

\section{Epidemiology}

Infectious curves reflected that this epidemic may be a mixed outburst pattern, with early cases suggestive with continuous common source, as potentially at Huainan Seafood Wholesale Market (HSWM), and later cases considered suggestive of a propagated source as the virus began to be transmitted from person to person[7].

The agent that causes this pathogen virus was identified on January 7, 2020 as a novel coronavirus, and genomic characterization and testing methodology development ensued. Now named as 2019-nCoV, the virus is very distinct from both MERS-CoV and SARS-CoV, yet closely related
[8]. Early cases were suggested that COVID-19 the new name for disease caused by the novel coronavirus may lead less severe than MERS and SARS. However, illness attack among so rapidly increasing numbers of persons and support evidence of human-to-human transmission suggests that 2019$\mathrm{nCoV}$ is more transmittable than both MERS-CoV and SARS-CoV[9].

\section{Symptoms}

The symptoms of COVID-19 infection started to appear after an incubation period of almost 5.2 days. The period from the attack of COVID-19 symptoms to death are ranged from 6 to 41 days with an average of 14 days[10]. Incubation period is dependent on the age of the patient and also depend on status of the patient's immune system. The patients $>70$-years old had shorter incubation period compared with those who are the under the age of 70 . The most common symptoms at attack of COVID-19 dry cough, illness are fever, and fatigue, while other symptoms include sputum production in lungs, diarrhea, headache, hemoptysis, lymphopenia and dyspnea[11].

In some cases, the multiple peripheral groundglass equivocation observed in sub-pleural regions of both lungs that likely induced both localized and systemic immune response that lead to increased inflammation. Regrettably, with interferon inhalation treatment of some cases showed no clinical effect and instead appeared to atrophy the condition by progressing pulmonary equivocation[12] 


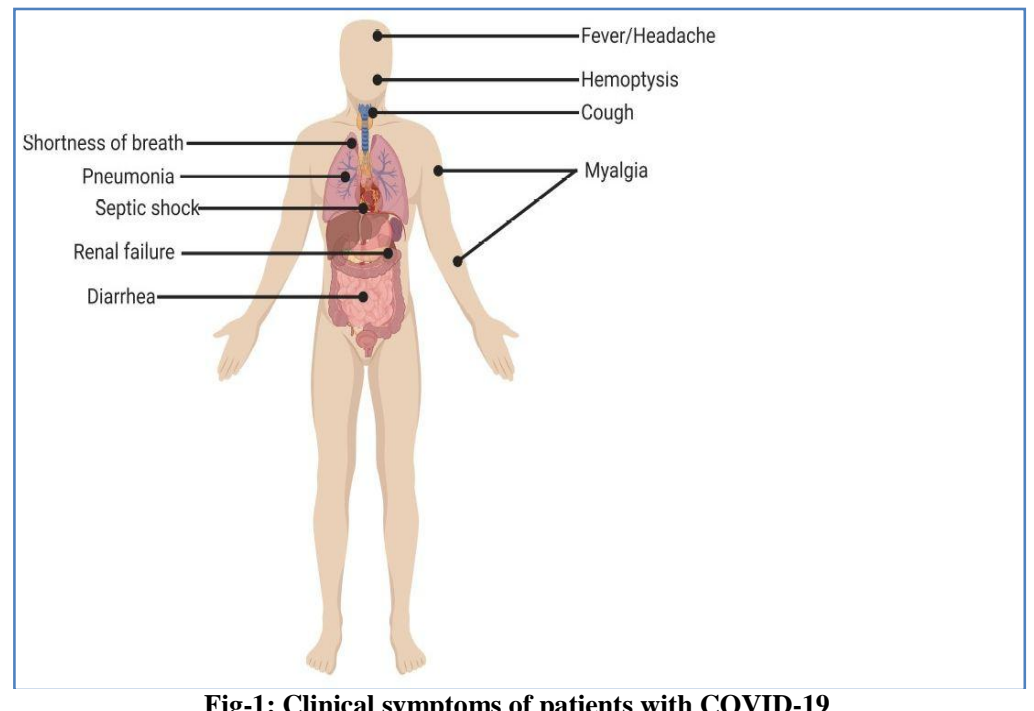

Fig-1: Clinical symptoms of patients with COVID-19

\section{Pathogenesis}

The patients infected with COVID-19 showed high number of leukocytes, abnormal respiratory findings and with pro-inflammatory cytokines. One of the Corona virus reported in a patient and showed fever with dry cough after 5 days, with body temperature at $39.0^{\circ} \mathrm{C}$. The patient's sputum showed positive real-time polymerase chain reaction (PCR) results that confirmed COVID-19 infection in patient[13,14]. Additionally, higher blood $\mathrm{C}$-protein showed in results which is a16.16 mg/L [12]. COVID-19 infection patients have seen many of inflammatory responses such as that included IL1RA,IL1- $\beta$, IL7, IL8, IL9, IL10, GCSF, basic FGF2, IFN $\gamma$, GMCSF, IP10, MIP1 $\alpha$, MIP1 $\beta$, MCP1, PDGFB, VEGFA and TNF $\alpha[16]$. There were some of the severe cases that admitted to the medical care unit carrying high levels of pro-inflammatory cytokines including GCSF, IL2, IL7, IL10, MCP1,TNF $\alpha$, IP10 and MIP1 $\alpha$ that were reasons to promote disease severity $[15,11]$.

\section{Vaccine Development}

Rapid reconstruction of SARS-CoV-2, and this technical advancement is very helpful for development of vaccine[17]. Rhesus monkey human ACE2 transgenic mouse for development of vaccine, and some SARS-CoV-2 vaccines are already under experimental clinical trial[18].Probably, the mechanism of vaccination offers the best option to control COVID$19[19,20]$.

\section{CONCLUSION}

In summary, an emerging human $\mathrm{CoV}$ is SARS-CoV-2, and which appears similar to previous MERS and SARS outburst. Bats are considered likely an important reservoir for SARS-CoV-2, and the current knowledge does not support the Huainan Seafood Market (HCMs) as the only source of infections. Mainly, SARS-CoV is transmitted through inhalation of respiratory droplets and direct or indirect contact, and infection has been evaluated to have median incubation period of 5.2 days and a R0 of 2.2. Finally more intercedes that will finally allow the effective control of this arising severe pandemic or viral infection

\section{REFERENCES}

1. Tyrrell, D. A. J., \& Bynoe, M. L. (1966). Cultivation of viruses from a high proportion of patients with colds. Lancet, 76-7.

2. Liu, Y., Gayle, A. A., Wilder-Smith, A., \& Rocklöv, J. (2020). The reproductive number of COVID-19 is higher compared to SARS coronavirus. Journal of travel medicine.

3. Remuzzi, A., \& Remuzzi, G. (2020). COVID-19 and Italy: what next? The Lancet.

4. Zheng, Y.Y. (2020). COVID-19 and the cardiovascular system. Nature Reviews Cardiology. 17(5): 259-260.

5. Perlman, S., \& Netland, J. (2009). Coronaviruses post-SARS: update on replication and pathogenesis. Nature reviews microbiology, 7(6), 439-450.

6. Stroup, D. F., Berlin, J. A., Morton, S. C., Olkin, I., Williamson, G. D., Rennie, D., ... \& Thacker, S. B. (2000). Meta-analysis of observational studies in epidemiology: a proposal for reporting. Jama, 283(15), 2008-2012.

7. Wu, Z., \& McGoogan, J. M. (2020). Characteristics of and important lessons from the coronavirus disease 2019 (COVID-19) outbreak in China: summary of a report of 72314 cases from the Chinese Center for Disease Control and Prevention. Jama, 323(13), 1239-1242.

8. Chowell, G., Abdirizak, F., Lee, S., Lee, J., Jung, E., Nishiura, H., \& Viboud, C. (2015). Transmission characteristics of MERS and SARS in the healthcare setting: a comparative study. $B M C$ medicine, 13(1), 210.

9. HuiDS, I. A. E., Madani, T. A., Ntoumi, F., Koch, R., \& Dar, O. (2020). The continuing 2019-nCoV epidemicthreatof novel coronaviruses to global 
health: the latest 2019 novel coronavirus outbreak in Wuhan, China. Int J Infect Dis, 91, 264-266.

10. Li, Q., Guan, X., Wu, P., Wang, X., Zhou, L., Tong, Y., ... \& Xing, X. (2020). Early transmission dynamics in Wuhan, China, of novel coronavirusinfected pneumonia. New England Journal of Medicine.

11. Huang, C., Wang, Y., Li, X., Ren, L., Zhao, J., Hu, Y., ... \& Cheng, Z. (2020). Clinical features of patients infected with 2019 novel coronavirus in Wuhan, China. The lancet, 395(10223), 497-506.

12. Lei, J., Li, J., Li, X., \& Qi, X. (2020). CT imaging of the 2019 novel coronavirus (2019-nCoV) pneumonia. Radiology, 295(1), 18-18.

13. Bernheim, A., Mei, X., Huang, M., Yang, Y., Fayad, Z. A., Zhang, N., ... \& Li, S. (2020). Chest CT findings in coronavirus disease-19 (COVID19): relationship to duration of infection. Radiology, 200463.

14. Chen, L., Xiong, J., Bao, L., \& Shi, Y. (2020). Convalescent plasma as a potential therapy for COVID-19. The Lancet Infectious Diseases, 20(4), 398-400.
15. Zhang, C., Shi, L., \& Wang, F. S. (2020). Liver injury in COVID-19: management and challenges. The Lancet Gastroenterology \& Hepatology, 5(5), 428-430.

16. Baud, D., Qi, X., Nielsen-Saines, K., Musso, D., Pomar, L., \& Favre, G. (2020). Real estimates of mortality following COVID-19 infection. The Lancet infectious diseases.

17. Prompetchara, E., Ketloy, C., \& Palaga, T. (2020). Immune responses in COVID-19 and potential vaccines: Lessons learned from SARS and MERS epidemic. Asian Pac J Allergy Immunol, 38(1), 1-9.

18. Peeples, L. (2020). News Feature: Avoiding pitfalls in the pursuit of a COVID-19 vaccine. Proceedings of the National Academy of Sciences, 117(15), 8218-8221.

19. Fauci, A.S., H.C. Lane, and R.R.(2020). Redfield, Covid-19-navigating the uncharted. 2020, Mass Medical Soc.

20. Bao, L., Deng, W., Huang, B., Gao, H., Liu, J., Ren, L., \& Qu, Y. (2020). The Pathogenicity of SARS-CoV-2 in hACE2 Transgenic Mice. bioRxiv. 